\title{
Enfoque CTS, o ensino médico e a ética de responsabilidade de Hans Jonas
}

\section{RESUMO}

Marlene Harger Zimmermann marlene hz@yahoo.com.br 0000-0001-7933-2056 Universidade Estadual de Ponta Grossa, Ponta Grossa, Paraná, Brasil.

\section{Rosemari Monteiro Castilho} Foggiatto Silveira foggiattorm@hotmail.com $0000-0002-0432-5182$

Universidade Tecnológica Federal do Paraná, Ponta Grossa, Paraná, Brasil. Bolsista de Produtividade em Pesquisa 2.

\begin{abstract}
A educação tecnológica no enfoque CTS assume importância ao remeter a interdisciplinaridade como riqueza na construção de pontes interligando diversos saberes no atendimento da complexidade inerente ao ser humano e a vida em sociedade. A presente reflexão teórica aponta para o urgente posicionamento dos atores sociais, entre eles o médico, diante da falácia de que a tecnologia é neutra não apresentando consequências. Mergulhados na sociedade tecnocrata com repercussões da medicina tecnocêntrica por meio do profissional médico tecnotrônico; a ética de Hans Jonas é aliada na tentativa de mudanças na formação do médico. Urgente suscitar reflexões sobre consequências que a tecnologia oferece a humanidade quando desprovida de aspectos humanos, sociais e ambientais. Compete à universidade salutar interlocução remetendo à necessidade de mudanças na tentativa de formar o profissional médico mais humanizado, preocupado com a manutenção da vida do homem na sociedade.
\end{abstract}

PALAVRAS-CHAVE: Ciência, Tecnologia e Sociedade (CTS). Ética. Educação médica. Responsabilidade social. 


\section{INTRODUÇÃO}

Nas últimas décadas, grande desenvolvimento da ciência e da tecnologia se fizeram presentes no contexto mundial, trazendo inovações, benefícios, realizando transformações em praticamente todas as áreas da sociedade. Dentre estas áreas, o ensino assume importância em suscitar reflexões que abarquem a relação do homem com o mundo em que habita; a relação entre Ciência, Tecnologia e Sociedade (CTS). Salienta-se que a palavra ensino é derivada do verbo ensinar, do latim insignare, marcar com um sinal, buscar e despertar para o conhecimento; conhecimento este que permite um descortinar de possibilidades (ANASTASIOU, 2004).

O movimento CTS há décadas vem sendo fonte de inspiração de diversos autores que se debruçam sobre a preocupante e instigante tarefa de reflexionar sobre o mundo da ciência e tecnologia e suas repercussões à sociedade; habitat natural do homem.

Em atendimento à luta e permanência das condições de saúde do homem inserido na sociedade, surge a figura do médico que necessita estar capacitado e habilitado para tal. O processo de formação recebe ajuda do ambiente acadêmico e assume importantíssima função ora contextualizando, ora reflexionando sobre os determinantes responsáveis pelo profissional crítico, ético e reflexivo, exigidos pelas Diretrizes Curriculares Nacionais vigentes para o curso de Medicina, aprovadas em 20/06/2014, por meio da Resolução CNE no3/2014; e assim dar devolutiva à sociedade que necessita de seu profissionalismo e de seus conhecimentos (BRASIL, 2014).

A responsabilidade na formação acadêmica do médico ultrapassa os saberes esperados na atuação profissional apontando para a responsabilidade social. Neste pensar, concorda-se com o pensamento de Sordi e Bagnato (1998) de que o processo pedagógico, que visa a construção do saber do indivíduo, deve estimular o ato reflexivo, desenvolvendo sua capacidade de observação, análise, crítica, autonomia de pensar e de ideias, ampliando os seus horizontes, tornando-o agente ativo nas transformações da sociedade, buscando interagir com a realidade na qual está inserido.

Salienta-se que esta profissão sofre repercussão direta do desenvolvimento científico e tecnológico, haja vista os avanços da biomedicina, nanotecnologia, engenharia genética (projeto genoma humano, clonagem), farmacogenética, cibernética, entre outros. Todo aparato técnico-científico tem como cerne o homem; tudo é feito e idealizado pelo, para e com o homem. Contudo, diante destes avanços emergem problemas e dúvidas até então sem precedentes na história da humanidade, o que suscita novos questionamentos na contemporaneidade: Será que todo desenvolvimento tecnológico é garantia de felicidade e resolução dos problemas sociais? A tecnologia associada à ciência pode trazer consequências irreversíveis e ameaçadoras para a vida humana? Como conciliar a humanização no contexto tecnológico tendo como premissa o valor da vida humana?

Sob este prisma abre-se um leque de possibilidades e de respostas. Bazzo (2015) salienta que a sobrevivência da sociedade está ameaçada pelo número crescente de problemas inéditos e muitos ainda não resolvidos, os quais 
permanecerão se a sociedade continuar com o que ele chama de sonambulismo tecnológico, de pensar no ter muito mais que no ser.

As questões relacionadas ao ter são responsáveis por um futuro nebuloso e preocupante para vários autores em relação à sociedade tecnocrática e seu consumismo, bem como a responsabilidade inerente ao ato de produzir sem refletir sobre possíveis consequências.

Neste pensar, a formação inicial do médico não pode esquivar-se da responsabilidade de formar profissionais que atendam às exigências por hora apresentadas, em que as questões pertinentes à ciência e à tecnologia sejam reflexionadas por conta do impacto de suas repercussões à vida na sociedade e o temor crescente em relação ao futuro da vida; bem como dos valores que a compõe, entre eles a ética.

A ética vem permeando a história da humanidade e seus questionamentos tornam-se mola propulsora na tentativa de nortear o agir humano na busca do bem. Diante de fatos ocorridos em que este agir foi contra o próprio homem, como no caso do uso da bomba atômica em 1945; novas reflexões se fizeram necessárias dando surgimento à Ética da Responsabilidade de Hans Jonas, a qual se fundamenta na heurística do temor, em relação ao futuro sobre o patrimônio mais sagrado da humanidade, a vida.

Diante do exposto, pergunta-se; qual a contribuição da ética da responsabilidade de Hans Jonas na formação do médico no contexto ciência, tecnologia e sociedade? Este artigo tem como objetivo reflexionar sobre a ética da responsabilidade de Hans Jonas e suas relações no ensino médico no contexto da ciência, tecnologia e sociedade.

Para alcançar objetivo traçado abordar-se-á sobre o enfoque Ciência, Tecnologia e Sociedade (CTS); a Tecnologia, Tecnociência e a Formação Médica. Posteriormente adentrar-se-á no pensamento ético de Hans Jonas (ética da responsabilidade) e sua relação com o ensino médico. Finalizar-se-á tecendo algumas considerações sobre a ética Hanseana no contexto CTS e ensino médico.

Salienta-se que o presente artigo é parte dos estudos relativos ao Doutorado do Programa de Pós-Graduação em Ensino de Ciência e Tecnologia da Universidade Tecnológica Federal do Paraná, Campus Ponta Grossa.

\section{METODOLOGIA}

Trata-se de pesquisa teórica, exploratória, crítica e reflexiva sobre o enfoque CTS e o Ensino Médico à luz da Ética da Responsabilidade de Hans Jonas.

Salienta-se que a pesquisa teórica é aquela que fornece discussões pertinentes sobre as condições da realidade. Não necessariamente implica imediata intervenção na mesma, contudo, seu papel é decisivo na criação de condições para tal (FANTINATO, 2015).

Já a pesquisa exploratória é definida por Gil (2002) como aquela que tem como principal finalidade desenvolver, esclarecer e aprimorar ideias com objetivo de formular problemas para futuras pesquisas. Moreira, Caleffe (2008) afirmam que elas são desenvolvidas com o intuito de proporcionar uma visão geral, do tipo aproximativo, sobre determinado fenômeno. 
A temática do presente artigo articula-se com o pensamento de relacionar a produção do conhecimento para ações que se voltem às mudanças tanto na esfera política, econômica como social as quais versem sobre a responsabilidade e a segurança advinda do uso da tecnologia pelo homem. Daí a escolha da pesquisa crítica tendo sua origem no trabalho de Paulo Freire e Paul Willis e expandida por teóricos da educação como Michael Apple e Henry Giroux (CARSPECKEN, 2011). Segundo o mesmo autor (CARSPECKEN, 2011, p.397), ela procura "compreender a si mesma como uma prática que trabalha com pessoas para conscientizar criticamente em vez de meramente descrever a realidade social".

A reflexão é parte integrante de uma pesquisa tendo em vista que toda produção do conhecimento utiliza-se da reflexão sistemática. Enquanto educador, o professor assume o compromisso de reforçar e desenvolver nos alunos a prática da habilidade reflexiva tornando-se esta imprescindível na formação. A evolução tecnológica e suas repercussões suscitam novos olhares que se desenvolvem mediante oportunas reflexões, quer seja na academia ou não.

\section{CIÊNCIA, TECNOLOGIA E SOCIEDADE}

Esses três construtos abrangem um universo de especificidades que estão inter-relacionadas. No dizer de Nunes (2000, p.121) "ciência e tecnologia necessitam uma da outra para seu desenvolvimento e se impelem mutuamente em direção a novos avanços". Em relação a tecnologia, ela se 'alimenta' do progresso, que como uma grande espiral, mobiliza-se num crescente continuun em que a saturação não acontece pelo seu dinamismo e pelas constantes inovações. As inovações suscitam sempre mais ascensão desta espiral rumo ao infinito e junto com ela as implicações inerentes de todo progresso, de toda tecnologia.

Segundo Cerezo (2003) a união da ciência à tecnologia foi responsável por avanços importantes no mundo principalmente após a segunda guerra mundial; os computadores eletrônicos (ENIAC, 1946), os transplantes de órgãos (Rins, 1950), o uso da energia nuclear para o transporte (USS Nautilus, 1954), o invento da pílula anticoncepcional (1955). Algumas inclusive aumentaram o poder de nações como, por exemplo, com o lançamento do primeiro satélite artificial ao redor da terra, Sputnik, em outubro de 1957, pela União Soviética; os países ocidentais e os Estados Unidos se deram conta do desenvolvimento científico e tecnológico daquele país e o que isso representava para o mundo.

O lançamento do referido satélite pela União Soviética, foi como um divisor de águas no que se refere a implementação e avanço rumo à sociedade tecnocrata. O mundo pode conferir o impacto que a tecnologia exercia e o quanto isso representava. Em resposta a isso, a partir de 1960, criou-se a robótica, transistores e semicondutores, laser, fibra óptica, microcomputadores e a informática. Houve conquista do espaço com o primeiro homem a pisar na lua e o advento da internet, do sistema digital e da telefonia celular que mudou radicalmente a comunicação no mundo globalizado. Inovações eletrônicas no campo da saúde por meio do tomógrafo, da ressonância, dos procedimentos endoscópicos se tornaram coadjuvantes na prática da medicina e de seus profissionais no diagnóstico e tratamento das doenças. Todavia, neste universo de tecnologia, facilmente maximiza-se a tecnociência minimizando o homem no conjunto de seus valores. 
Parece que tudo está reduzido à ciência e à tecnologia tornando-se o homem objeto de manipulação do progresso tecnológico (MIRANDA, 2000).

Apesar das benesses, os problemas também se fizeram presentes, no decorrer do século XX, por conta da sucessão de desastres vinculados ao desenvolvimento científico e tecnológico descontrolado; vazamento de resíduos contaminantes, acidentes em reatores nucleares, efeitos colaterais por fármaco (talidomida), derramamento de petróleo, uso de praguicidas, etc. Problemas com repercussão na esfera ambiental, ética, filosófica, política, econômica, cultural e sociológica; sendo o homem ameaçado, sinalizando para a necessidade de participação popular nas discussões sobre o contexto da ciência, da tecnologia e da sociedade.

Estes acontecimentos, na tentativa de coibir ou minimiza-los, se tornaram pauta de ações/reflexões do movimento CTS que teve sua origem a partir da década de 1970. Tendo como objetivo o desenvolvimento crítico do uso da Ciência e da Tecnologia e seus efeitos à Sociedade (SCHNORR e RODRIGUES, 2015).

Em 1999, a cidade de Budapest, na Hungria, foi palco de importantes discussões sobre a renegociação das relações entre ciência e sociedade no Congresso Mundial sobre a Ciência, organizado pela UNESCO e pelo Conselho Internacional da Ciência (ICSU), com aprovação de importantes documentos abordando temas como reorientação das prioridades de investigação para as necessidades reais da população, mudanças na educação cientifica e nos modelos de comunicação da ciência, etc. Denotou-se que os avanços científicos tecnológicos não respondiam às expectativas e necessidades do mundo no fim daquele século. Isto por conta da complexidade da temática em suas dimensões acadêmica, ética, política, econômica e educativa (CEREZO, 2003).

O movimento CTS tem preocupação em romper com a ideia de neutralidade da ciência pelo pensamento vigente a partir do século XVII até então considerado como fonte de conhecimento inquestionável, seguro, verdadeiro (ANDRADE e SILVEIRA e SAUER, 2014). Rompimento do chamado modelo linear do desenvolvimento com a falsa afirmação de que quanto mais ciência se possui, mais tecnologia se obtém o que resulta em mais riqueza e, por conseguinte o aumento do bem estar social. Neste pensar, a técnica seria responsável em trazer a felicidade e resolver todos os problemas sociais (CEREZO, 2002; PINHEIRO, SILVEIRA, BAZZO, 2009; BAZZO, 2014; CANCHUMANI, 2010).

\section{TECNOCIÊNCIA, TECNOLOGIA E A FORMAÇÃO MÉDICA}

São notórias as transformações ocorridas no contexto mundial nos últimos tempos, sob a égide da ciência e da tecnologia. O desenvolvimento tecnológico é fruto do desenvolvimento da ciência que num processo de interação constituem a tecnociência. Esta por sua vez, ao vincular-se com a medicina, suscitou avanços por meio de novos medicamentos, das máquinas de diálise, dos respiradores, técnicas de transplante de órgãos, alimentação e hidratação artificial, Unidades de Cuidados Intensivos, inseminação artificial, etc. (DRANE e PESSINE, 2005).

No âmbito da saúde, a invenção do estetoscópio, pelo médico francês RenéTheóphile-Hyacinthe Laënne, em 1816; foi considerada a tecnologia médica inicial Helmholtz em 1850; o laringoscópio desenhado por Johann Czermak em 1857 e a 
descoberta dos raios X desenvolvidos por Wilhelm Roentgen, em 1895 (POSTMAN, 1994).

Sob o prisma dos benefícios salienta-se que mediante a utilização da tecnologia, curas para doenças puderam ser descobertas, instrumentos desenvolvidos, máquinas facilitaram o trabalho do ser humano e a reciclagem do lixo pôde acontecer (MONASSA, 2011). A tecnologia trouxe rapidez e minimização de invasão do organismo como no caso do uso dos laparoscópios, câmaras de televisão que são inseridas para retiradas da vesícula biliar, por exemplo. A descoberta do laser, na década de 60 ocasionou verdadeira revolução na área médica. Considerada uma das tecnologias mais importantes desenvolvidas pela humanidade por sua diversidade de utilizações, indo desde a leitura de códigos de barra a procedimentos médicos (AVANCINI, 2015). Entre as principais vantagens do laser, salienta-se rápida cicatrização, poder anti-inflamatório, ausência de dor e de sangramento e facilidade de aplicação.

Nos anos 40 com o surgimento dos antibióticos associado ao desenvolvimento dos laboratórios de diagnósticos, a medicina avançava a passos largos distanciando-se do paciente. Esta prática médica havia entrado em novo estágio, que de acordo com Neil Postman (1994, p.107):

\footnotetext{
O primeiro se caracterizava pela comunicação direta com as experiências dos pacientes, com base nos relatos destes, nas perguntas e observações do médico. O segundo se caracterizou pela comunicação direta com os corpos dos pacientes pelo exame físico [...]. O estágio em que nos encontramos agora se caracteriza pela comunicação indireta com a experiência e corpo do paciente por meio de maquinaria técnica. [...] patologistas e radiologistas que interpretam o significado de informação técnica e não tem, em absoluto, a menor relação com o paciente, apenas com tecidos e fotografias.
}

O progresso trouxe para a humanidade inúmeros benefícios, porém sofre as consequências do condicionamento materialista, mecanicista, tecnicista e reducionista, que estão implícitas no paradigma cartesiano. Houve dicotomia entre ciência e ética, entre o agir moral e o agir técnico, gerando um assustador processo de desumanização. Segundo Cardoso (1995), o homem atual separou a razão do sentimento, a ciência da ética, a utilidade da felicidade. Perdeu-se a percepção da realidade como um todo.

Segundo Rodrigues (2003, p.5) "as transformações ocorridas no mundo através do lluminismo Filosófico, da Revolução Científica e Industrial, são a razão de ser do paradigma tecnicista, que durante muito tempo tem influenciado o pensamento humano". O universo, a partir de Descartes, foi compreendido como máquina e a natureza funcionava de acordo com leis rígidas mecânicas. Transpondo para a medicina, o corpo humano foi considerado como máquina que pode ser analisado com suas diferentes peças e a doença como mau funcionamento dos mecanismos biológicos. Daí a ênfase na doença ao invés do doente em sua totalidade e integralidade, fazendo com que se perca de vista a pessoa doente. A abordagem reducionista da medicina faz o médico ver a saúde como mero funcionamento mecânico do organismo, muitas vezes perdendo de vista o paciente como ser humano (DRANE e PESSINE, 2005).

Esta perspectiva reducionista é a responsável pela objetividade do fazer médico traduzido em medidas, manipulações, análises e intervenções, deixando 
de lado valores tais como amizade, interesse, respeito, confiança (DRANE e PESSINI 2005).

Descartes ressaltava o papel do sujeito, baseando seu método na dúvida, na divisão, na indução e na revisão. Para ele, a razão é quem oferece o critério de verdade. "A concepção racional, reducionista, especializada, simplificada e fragmentada do mundo, encontrada no racionalismo cartesiano, leva à separação do sujeito-objeto" (RODRIGUEZ, 2003, p. 56). Esta dicotomia pode ser responsável pela divisão do conhecimento em disciplinas e especializações cada vez mais numerosas. Aguiar (2001) citado por Rodriguez (2003, p. 66) contribui quando afirma que "a aplicação do reducionismo ao campo da saúde alimenta a crescente especialização dos médicos, processo que tem como consequência a fragmentação dos pacientes em órgãos e sistemas".

Fator este que gerou na profissão médica dificuldade da visão integral do homem com sua subjetividade, sua impessoalidade. O médico passou a visualizar o paciente como doença em detrimento do doente com ênfase da denominação "caso", "número", havendo despersonalização do sujeito envolvido. O paciente encontra dificuldade em sentir-se como ator principal, sujeito autônomo, possuidor do direito de decidir sobre seu tratamento, seu diagnóstico, ou seja, alguém que participa das decisões.

Segundo Moraes (2001), a visão mecânica separa os indivíduos de seus relacionamentos, não reconhecendo a importância do contexto em que estão inseridos, gerando um individualismo exagerado, em que prevalece o egocentrismo humano. Observa-se também a ausência de ética e de solidariedade onde os significados do amor e da compaixão são perdidos. Maria Cecília de S. Minayo (2000, p.59) contribui afirmando que:

\footnotetext{
A concepção positivista da ciência universal, atemporal e isenta de valores conduzindo os rumos da humanidade, na área da saúde foi sendo problematizada por um debate teórico e ideológico que engajou questões tanto de cientificidade dos postulados vigentes como da ética de investigação científica.
}

E se ainda não bastasse; o impulso gerado pela produção e aquisição de equipamentos, cuja tecnologia causa fascínio, é um dos responsáveis, muitas vezes pelo consumismo desenfreado desacompanhado de importantes reflexões acerca de repercussões a curto e longo prazo sem contar com o acesso restrito a determinados produtos consumidos.

A área da saúde não é imune a esse processo. Os recursos tecnológicos desenvolvidos nesta área, nem sempre estão disponíveis para todos da sociedade. A alocação dos recursos é restrita sem atendimento a demanda; gerador de descontentamento e desigualdades. Neste contexto, percebe-se que muitas vezes, a vida, valor supremo passa a objetivar-se, (tornar objeto), tornando-se a tecnociência maximizada num processo de fragmentação, de desvalorização, de desconstrução do indivíduo. As repercussões atingem as ações do profissional médico em toda sua prática, principalmente a hospitalar, local que se concentram os aparatos tecnológicos, separando "cada vez mais o profissional do cuidado mais efetivo e afetivo" (FIGUEIREDO e VIANA, 2006, p. 372).

Na formação médica a tecnologia continua exercendo seu espaço, contudo, o docente deve ficar atento para evitar que o futuro profissional se torne cada vez 
mais distante do respeito ao desejo do paciente, o dono do "corpo que está sendo tratado" e muitas vezes o leva a cometer erros por se considerar "dono do saber" e não escutar a opinião do "dono do corpo" (KOIFMAN, 2001).

O sistema médico atual fundado na alta tecnologia tem como resultado o empobrecimento da comunicação interpessoal em que a palavra e o diálogo são suprimidos. Nesse pensar, Pessini e Barchifontaine (2007, p. 196) expressam que "começa a imperar na medicina a tecnologia (adoração da técnica)". "A medicina é sobre a doença, não sobre o paciente. E o que o paciente sabe não é digno de confiança; o que a máquina sabe é confiável" (POSTAMN, 1994, p. 106). Está-se diante da medicina tecnocêntrica, que se encontra cada vez mais difundida no mundo.

Por conseguinte, Sanvito (1994), citado por Pessini e Barchifontaine (2007) aponta três tipos fundamentais de médicos; o médico-humano que exerce a medicina tendo como centro o paciente; o médico-sábio que exerce a medicina tendo as doenças como centro e o médico-tecnotrônico aquele que o futuro do paciente não está mais em suas mãos, mas sim na tecnologia. A tecnologia tem sido considerada um dos grandes fatores de afastamento na relação médico paciente, colaborando na despersonalização e a perda da individualidade, privacidade, subjetividade e singularidade dos indivíduos.

Quando um profissional da saúde se aproxima do doente, ele está se aproximando de uma pessoa cujo corpo não é objeto de intervenção, mas sim um sujeito autônomo, livre, responsável, consciente, possuidor de valores morais, culturais e espirituais, membro de uma família e inserido em uma sociedade. Segundo Sgreccia (2002, p. 127) "em todo ato médico e em toda intervenção na corporeidade não poderá deixar de estar presente esta riqueza e esta ligação: é ato de uma pessoa sobre outra pessoa com a mediação corpórea". Lembrando ainda que toda doença tem sempre um rosto humano. Daí a necessidade dos profissionais de saúde serem pessoas reflexivas, humanas e com visão integral e não reducionista.

O enfoque tecnológico é também influenciado pelo sistema econômico vigente. O capitalismo visa produção cada vez maior e em menor tempo, objetivando o lucro, cuja preocupação com o futuro do homem e com o meio ambiente ganha expressão. Como exemplo, cita-se as pesquisas envolvendo seres humanos, a fertilização in vitro, a clonagem, as células-tronco, os transgênicos, etc. O lucro que se pretende, gera competição desmedida. Nesse pensar, Figueiredo e Viana contribuem dizendo (2006, p. 380): "Se o critério do ato humano é o lucro, as violações monstruosas da dignidade humana são inevitáveis".

Diante desse cenário o ensino não está incólume da responsabilidade que lhe é atribuída enquanto formadora de cidadãos. São das universidades e escolas que saem os profissionais para atuar na sociedade. Há, portanto, grande parcela dos envolvidos neste cenário de formação, em especial dos professores no dever de fomentar discussões sobre o desenvolvimento tecnológico em paralelo com o desenvolvimento humano e suas repercussões no contexto social. Valores humanos, sociais, éticos necessitam ser relacionados com a construção do conhecimento em ciência e tecnologia na tentativa de promover o "bem-estar nas pessoas, além de reforçar as atitudes humanas no seu desempenho profissional" (BAZZO, 2014, p. 20). 
É notório que a sociedade está exigindo uma nova visão de mundo, diferente, não fragmentada. Daí a necessidade de unir as partes deste homem "esfacelado", para alcançar uma visão de totalidade. Urgente se faz o repensar da formação do profissional médico em busca de benefícios e da garantia da integridade do ser humano, tendo como norteador o princípio da dignidade humana. De acordo com Oliveira (2000, p. 61), "é fundamental que lutemos para substituir o enfoque tecnológico pelo humanitário na medicina".

$\mathrm{Na}$ formação do médico importante que haja debates e reflexões sobre a necessidade dos avanços científicos agregados ao desenvolvimento de aparatos tecnológicos e as possíveis repercussões das tomadas de decisão. Atualmente questões relacionadas com a decodificação do genoma humano são preocupantes tendo em vista a imprevisibilidade da manipulação das informações dos agentes responsáveis pela vida. Este saber pode ser o responsável por desastres, por consequências incertas e até nefastas, geradoras de apreensão. Daí a importância de que assuntos similares a este sejam discutidos, analisados a luz da tríade ciência, tecnologia e sociedade para que o futuro da humanidade não seja ameaçado no estatuto da vida, da sobrevivência.

Essas reflexões corroboram para a necessidade de reformulação do ensino médico apontando para uma visão diferenciada e mais abrangente do profissional e de suas atitudes no que se refere à vida. Outrossim, devido a complexidade dos temas na área da saúde e das relações que possuem com o homem, há necessidade da integração cada vez maior dos diferentes saberes, dando lugar a um modelo de construção coletiva. No dizer de Koifman (2001), é possível identificar dois processos quase independentes: uma extensa formação clínica, centrada nas ciências biomédicas que reforça a prática individualista da medicina e uma abordagem social, incapaz de redefinir criticamente essa formação e seus diferentes tipos de prática.

Diante deste contexto, entende-se a educação como importante instrumento detentor de espaço para reflexões almejando mudanças necessárias de conduta de vida. A educação tecnológica vem em auxílio na tentativa de, por meio da crítica, da reflexão, da análise e do debate; conscientizar os atores sociais sobre a problemática da produção tecnológica e suas mazelas, a fim de que atitudes possam ser tomadas na construção de uma sociedade mais humanizada. Porém, no dizer de Silveira e Bazzo (2007, p. 3) “o grande desafio está em proporcionar uma educação tecnológica em nível superior fundamentada no desenvolvimento do conhecimento científico-tecnológico em sintonia com a realidade social, articulando as várias dimensões de educação, sociedade, ciência e tecnologia". Associado ao processo de educacional, o pluralismo metodológico pode ser instrumento importante à formação do aluno oportunizando-o a pensar e a refletir para que haja mudanças necessárias.

Desafio este que tem sido enfrentado por muitos pesquisadores levando-os a incansável busca para que aconteça a tão desejada união das áreas humanas com a tecnológica ampliando desta maneira a compressão da complementariedade de ambas numa construção de sociedade em que os valores humanos ganhem significância no desenvolvimento cientifico-tecnológico.

Quanto a formação médica, importante ressaltar que a vida humana requer a afirmação de Drane e Pessini (2005, p. 54) que "os médicos de hoje tendem a 
avaliar seu desempenho mais pela competência técnica objetiva do que por seu cuidado pessoal com os pacientes". Portanto, esforços são salutares para um ensino centrado em competências e habilidades capazes de elevar os valores como respeito à vida numa visão humanizada com supremacia da pessoa em detrimento da máquina, da tecnologia dispondo o conhecimento a serviço dos valores éticos, morais e humanísticos.

Precisa-se propiciar ao aluno metodologias que o ajudem a desenvolverem mais a intuição, a criatividade, a sensibilidade e o sentimento, para que ele possa perceber a realidade do outro. Sob esta ótica, o profissional reconhece o paciente como sujeito, respeita sua individualidade, integralidade e dignidade, valorizando sua autonomia em relação ao tratamento e ao uso da tecnologia. Trabalha na recuperação e promoção da saúde das pessoas, trata o doente da doença e não simplesmente a doença do doente.

Desta feita, médico e paciente inseridos em uma mesma sociedade tecnológica; podem exercitar-se em um continuo respeito pela dignidade que os constituem enquanto pessoa resultando em atitudes de humanização entre ambos e terreno fértil para a eticidade. A salutar associação entre competência e a consciência de valores traz repercussões importantes individuais e para a sociedade. Neste pensar, Sgreccia afirma que:

[...] é no momento operativo que se desenvolve a vida ética e se realizam os valores. Essa operacionalização, quando conduzida de acordo com a coerência entre e competência específica e a consciência dos valores, torna ética a ação em si e contribui para o enriquecimento do ser pessoal, tanto do profissional como do doente, bem como da sociedade.

Assim, a consciência dos valores assume importância em relação ao desenvolvimento da vida ética. Por conseguinte, quanto mais rica ela for; tanto mais atenta e sensível será a do profissional, com possibilidades de oferecer assistência humanizada e integral.

À medida que a prática médica se tornou mais poderosa por conta dos avanços da tecnociência e da tecnologia, os problemas éticos aumentaram e questionamentos surgiram. Toda tecnologia na área da saúde seria mesmo benéfica e auxiliaria na qualidade de vida das pessoas? Esses avanços teriam impactos negativos para a sociedade e o meio ambiente? Como ficaria a confiança dos indivíduos em relação ao médico quanto à necessidade do uso de tais tecnologias? E em relação ao interesse dos pacientes, estas tecnologias seriam usadas pelos médicos em atendimento ao desejo dos mesmos?

É urgente que a formação médica seja repensada, que assuma perfil generalista voltada para assistência integral, humanizada e para o trabalho em equipe em prol de benefícios para todos em sociedade sabendo quais os problemas de saúde da comunidade e as implicações da tecnologia hoje e amanhã. Há necessidade de "uma nova forma de ver a tecnologia no mundo contemporâneo" (BAZZO, 2015, p.28). Portanto, é no espaço da academia que o estudante de medicina deve ser instigado a refletir sobre estes aspectos e não "se constituir como mero repositório de conhecimentos, uma espécie de médico programado para procedimentos técnicos, que sabe tudo da máquina e nada do 
A ética vem como instrumento auxiliar a formação do profissional de saúde, ao relacionar-se com a ciência e a tecnologia, na tentativa do respeito à vida, a humanização do atendimento e a proteção à pessoa em relação ao futuro na sociedade. Está-se falando da ética da responsabilidade, condição sine quanon para a perpetuação da vida em sociedade diante do futuro tecnológico que se avizinha.

\section{ÉTICA DA RESPONSABILIDADE DE HANS JONAS E O ENSINO MÉDICO}

$\mathrm{Na}$ teia que se forma entre a ciência, tecnologia, sociedade e o poder que assumem diante do homem e da natureza, inúmeras reflexões e posicionamentos éticos tem surgido na tentativa de contribuir para que a vida humana em sociedade não seja dizimada e seu valor não seja negligenciado em nome da ciência e da tecnologia.

Neste pensar, salienta-se a ética da responsabilidade idealizada por Hans Jonas, emergida de sua experiência pós-guerra com a traumatizante experiência vivenciada pelo uso e destruição da bomba atômica em Hiroshima e Nagasaki em 1945. Hans Jonas, um dos maiores filósofos contemporâneos, nascido na Alemanha em 1903 e falecido em 1993 nos Estados Unidos teve como mestres Husserl, Heidegger e Malburg. Por conta do nacional socialismo deixa a Alemanha em 1933, se dirige a Israel para atuar na força sionista e depois ao exército britânico. Sua experiência como soldado o remete a necessidade de repensar a ética.

Foi professor no Canadá e nos Estados Unidos. Neste último, publica em 1966, filosofia sobre a biologia e em 1979, publica sua obra mais importante, "Das Prinzip Veratwortung- Versuch einer Ethic für die Technologische Zivilisation" (O Princípio Responsabilidade: Ensaio de uma ética para a civilização tecnológica) e em 1984 "Technik, Medizin und Ethik" (Técnica, Medicina e Ética). Em 1987, recebe em Frankfurt o prêmio da Paz tendo como pressuposto de que a Paz estaria diretamente relacionada à Responsabilidade e o filósofo em questão havia feito uma ponte entre ambas (COVOLAN, 2000).

Para Hans Jonas o progresso da técnica e da ciência apresenta ameaça para o futuro da humanidade e é neste cenário que a ética da responsabilidade ganha expressão. Suas reflexões retomam questões que envolvem relação entre Ser e Dever; Causa e Fim, Natureza e Valor e devem permear como seiva ações frente aos novos problemas advindos do progresso. Hans Jonas tem como pressuposto de que a força dinâmica sobre a natureza e o homem, advindas da liberdade deste, adquire também responsabilidade crescente em relação à manutenção da vida do homem na terra e na sua transcendência tanto no presente quanto no futuro.

Fundamenta-se, portanto, na heurística do temor "que somente através da compreensão do risco, que o ser humano passa a ocupar-se sobre o conflito" (OGIBOSKI, 2012, p.10) e que devem ser priorizadas as possíveis consequências dos atos advindos com a contribuição da ciência e da tecnologia (NUNES, 2000). O homo faber, o detector da techne, passa a ter maior importância do que o homo sapiens, ou seja, "a prática passa a dar as ordens e a comandar o agente gerador do saber" (IGLESIAS, 2000; p.76). Sob este arcabouço, há necessidade de reflexão paradigma ético do que devo fazer (COVOLAN, 2000). 
De acordo com Santos (2009), o pensamento de Jonas é atual por preocuparse com o futuro da humanidade e a humanidade futura. Partindo-se do pressuposto que às ações humanas derivam da técnica e do saber científico há necessidade de colocar o problema da tecnologia e da ciência sob reflexões filosóficas e éticas.

Hans Jonas em sua obra, 'O Princípio da Responsabilidade', afirma que o agir humano exige uma ética de previsão e de responsabilidade tendo em vista que o próprio homem passou a figurar entre os objetos da técnica, ou seja, habilitou-se a refabricar a si mesmo nas perspectivas do prolongamento da vida, controle do comportamento e da manipulação genética (JONAS, 2006).

O homem que usa de seu conhecimento científico para ser testado no próprio homem, tornando este último objeto da técnica e que coloca o aspecto evolutivo em suas próprias mãos; sugere um risco desmedido para o futuro da humanidade, o futuro do homem. No dizer de Oliveira (2013) esta aparência de plena liberdade conferida ao homem no poder da técnica de fazer escolhas sobre si mesmo, essa auto-reificação que permite-lhe não morrer, não sofrer e ser manipulado geneticamente antes de seu nascimento; é um tanto perigosa. Aspectos estes importantes de serem abordados na formação de futuros profissionais médicos com atuação em pesquisas e experimentos.

A primeira formação, no ambiente acadêmico, é local propício para se analisar e refletir sobre tais possibilidades e suas repercussões para a sociedade, o ethos humano, na tentativa de salientar a ética da reponsabilidade para uma vida plena de valores e não determinada aos toques dos botões eletrônicos, apenas (BAZZO, 2015).

Deve-se investir para que o futuro médico seja detentor de um conhecimento crítico e ampliado voltado para o bem-estar da vida na sociedade. Isto dependerá muito da percepção dos docentes cujas ações deverão estar voltadas para este grande desafio, a sobrevivência do homem na sociedade e o resgate de valores que constroem a solidariedade, a paz e a ética da responsabilidade.

\section{CONSIDERAÇÕES FINAIS}

A vida no mundo globalizado, regido pela ciência e tecnologia com repercussão dos seus resultados na sociedade traz consigo desafios que geram determinadas incertezas. Incertezas essas quanto aos rumos que serão tomados, aonde se pretende chegar e a qualidade de vida daqueles que ocuparem o espaço da chegada.

A tríade ciência, tecnologia e sociedade têm o seu existir por conta do homem que vive no mundo e para o mundo, na vida em sociedade. Por conseguinte, necessitam estar em consonância a fim de que o valor da vida possa ser preservado e respeitado na contemporaneidade e num futuro que se aproxima.

Concorda-se com a afirmação "a educação incorpora intrinsecamente em seu papel, preparar profissionais críticos e reflexivos em relação ao desenvolvimento de inovações tecnológicas e suas implicações sociais" (SILVEIRA E BAZZO, 2007, p.2). Implicações essas que têm repercussão em todas as áreas da sociedade, sendo a educação tecnológica necessária e de vital importância na tentativa de 
minimizar as repercussões da medicina tecnocêntrica por meio do profissional médico tecnotrônico.

Desta feita, é de extrema importância que a formação do médico seja revista contemplando aspectos sobre os rumos da atuação deste para o resgate de uma medicina mais humana. Na sociedade tecnológica em que se vive, é premente questionar-se sobre os efeitos colaterais da técnica.

A tecnologia, a ciência e a sociedade necessitam de princípios na tentativa de evitar-se a destruição do homem e de seu habitat natural. A ética da responsabilidade surge então como luz nestes tempos em que imperam a desumanização, a despersonalização e o predomínio da tecnologia com a falsa afirmação de bem-estar e de felicidade.

Depende de cada um em particular e em especial dos formadores dos profissionais médicos o exercício de refletir sobre o que foi exposto nestas linhas. A esperança reside em que novas gerações possam ser beneficiadas cuja vida do homem continua sendo a mola propulsora de todos os esforços. 


\title{
CTS approach, the medical educationl and Hans Jonas ethics of responsibility
}

\begin{abstract}
The technological education in CTS approach assumes significance by referring interdisciplinarity as wealth in the construction of bridges linking diverse knowledge in addressing the complexity inherent to the human being and life in society. This theoretical reflection points to the urgent positioning of social actors, including the doctor, on the fallacy that technology is neutral showing no consequences. Dipped in technocratic society with repercussions of technocentric medicine through tecnotrônico medical professional the ethics of Hans Jonas is allied in trying to change in medical training. Urgent raise reflections on consequences that technology offers humanity when deprived of human, social and environmental aspects. It is for the university, dialogue referring to the need for changes in an attempt to form the professional more humane doctor, concerned with the maintenance of human life in society.
\end{abstract}

KEYWORDS: Ethics. Medical education. Social responsibility. 


\section{REFERÊNCIAS}

AGUIAR, Adriana Cavalcanti de. Tendências na educação médica: um modelo curricular ajustado ao conceito ampliado de saúde, às mudanças tecnológicas e à realidade social. In: ARRUDA, B.K.G. de (Org.). A educação profissional em saúde e a realidade social. Recife: IMIP e Ministério da Saúde, 2001. p. 69-86.

ANASTASIOU, Lea. Ensinar, aprender, apreender e processos de ensinagem. In: ANASTASIOU, L. G.C.; ALVES, L.P. Processos de Ensinagem na Universidade. Joinville, SC: UNIVILLE, 2004.

ANDRADE, Rodrigo Pinto; SILVEIRA, Rosemari Monteiro Castilho Foggiato; SAUER, Elenise. Ensino na função orgânica, álcool, a partir de temas controversos. In PILATTI, Luiz Alberto; SILVA, Sani de Carvalho Rutz (org.) Pesquisa em Ensino de Ciência e Tecnologia. 1ạ ed. Curitiba: Ed. UTFPR, 2014.

AVANCINI, Marta. Luz na Medicina Revista Pré-Univesp on-line. [on-line]. São Paulo, junho de 2015, no 45. Disponível na Internet: < http://pre.univesp.br/luzna-medicina\#.Vj3wI7erTIV> ISSN 2357-7622.

BAZZO, Walter Antonio. De Técnico e de Humano: questões contemporâneas. Florianópolis: Ed. da UFSC, 2015.163 p.

Ciência, Tecnologia e Sociedade e o contexto da educação tecnológica. 4. Ed. rev.- Florianópolis: Ed. da UFSC, 2014, 296 p.

BRASIL. Resolução n. 3, de 26 de junho de 2014: Institui as Diretrizes Curriculares Nacionais do Curso de Graduação em Medicina. Disponível em: http://www.mec.gov.br. Acesso em: 19 ago. 2014.

CANCHUMANI, Roberto Mario Lovón. A propóstioc da construção de indicadores de Ciência e Tecnologia no Brasil: aspectos sociotécnicos. Revista De Ciência da Informação. v.11, n.3, jun/10.

CARDOSO, Clodoaldo Meneguello. Canção da Inteireza: uma visão holística da Educação. São Paulo: Summus, 1995

CARSPECKEN, P.F. Pesquisa Qualitativa Crítica: conceitos básicos. Rev Educação e Realidade, Porto Alegre, v. 36, n. 2, p. 395-424, maio/ago. 2011. 
COVOLAN, Nádia T. Técnica, Liberdade e Dever na Visão de Hans Jonas. In BASTOS, João Augusto de Souza Leão de Almeida (Org). Desafios da Apropriação do Conhecimento Tecnológico. Rev.- Curitiba: CEFET-PR, 2000.99p.(Coletânea "Educação e Tecnologia- CEFET-PR)

CEREZO, José A. López. Ciencia, técnica y sociedade in IBARRA, Andoni; OLIVÉ, Léon. Cuestiones éticas em ciência y tecnologia em el siglo XXI. Madrid, 2003.

DRANE, James; PESSINI, Leo. Bioética, medicina e tecnologia: desafios éticos na fronteira do conhecimento humano. São Paulo: Centro Universitário São Camilo: Edições Loyola, 2005.

FANTINATO Marcelo Métodos de Pesquisa. PPgSI, EACH, USP; 2015. Disponível emhttp://each.uspnet.usp.br/sarajane/wpcontent/uploads/2015/09/M\%C3\%A9todos-de-Pesquisa.pdf . Acesso em 10 de maio de 2017.

FIGUEIREDO, Nébia Maria Almeida de; VIANA, Dirce Laplaca. Fundamentos do uso de tecnologia em enfermagem. São Caetano do Sul, SP: Yendis Editora, 2006.

IGLESIAS, José Carlos. A heurística do temor na ética da preservação de Hans Jonas. In: SIQUEIRA, José Eduardo; PROTA, Leonardo; ZANCANARO, Lourenço. Bioética, estudos e reflexões. Londrina: Ed. UEL, 2000

JONAS, Hans. O princípio da responsabilidade: ensaio de uma ética para a civilização tecnológica. Tradução do original alemão Marijane Lisboa, Luiz Barros Montez. Rio de Janeiro: Contraponto: Ed. PUC-Rio, 2006.354p.

KOIFMAN, Lilian. O ensino médico no Brasil e na Argentina: uma abordagem comparativa. Tese. Fundação Oswaldo Cruz, 2001.

MINAYO, Maria Cecília de S. O desafio do conhecimento: pesquisa qualitativa em saúde. 5 ed. São Paulo: Hucitec, 2000

MIRANDA, Juranda Maia. Tecnociência, autonomia e dignidade humana na área da sáude. In: SIQUEIRA, José Eduardo; PROTA, Leonardo; ZANCANARO, Lourenço. Bioética, estudos e reflexões. Londrina: Ed. UEL, 2000.

MONASSA, Clarissa Chagas Sanches. Sociedade Tecnológica: relações jurídicas internacionais de comércio à luz do princípio da ética da responsabilidade de Hans Jonas.1aed. São Paulo: Letras Jurídicas , 2011. 170p. 
MORAES, Maria Cândida. O paradigma educacional emergente. Campinas: Papirus, 2001.

MOREIRA Herivelto; CALEFFE, Luiz Gonzaga. Metodologia da pesquisa para o professor pesquisador. 2ª ed. Rio de Janeiro: Lamparina, 2008.

NUNES, Amauri Porto. As implicações éticas da manipulação genética em seres humanos segundo o Princípio da Responsabilidade de Hans Jonas. In: SIQUEIRA, José Eduardo; PROTA, Leonardo; ZANCANARO, Lourenço. Bioética, estudos e reflexões. Londrina: Ed. UEL, 2000.

OGIBOSKI, Vitor. Reflexões sobre a tecnociência: uma análise crítica da sociedade tecnicologicamente potencializada. 2012. 104f. Dissertação (Mestrado em Ciência, Tecnologia e Sociedade) - Centro de Educação em Ciências Humanas. Universidade Estadual de São Carlos, São Carlos. 2012.

OLIVEIRA, Jelson Roberto de. O homem como objeto da técnica segundo Hans Jonas: o desafio da biotécnica. Problemata: R. Intern. Fil. Vol. 04. No. 02. (2013), p. 1338 ISSN 15169219.

OLIVEIRA, Fátima. Bioética: uma face da cidadania. São Paulo: Moderna, 2000.

PINHEIRO, Nilcéia Aparecida Maciel, SILVEIRA, Rosemari Monteiro Castilho Foggiatto; BAZZO Walter Antônio. O contexto científico-tecnológico e social acerca de uma abordagem crítico-reflexiva: perspectiva e enfoque. Revista Iberoamericana de Educación n. 49/1 - 25 de marzo de 2009 EDITA: Organización de Estados Iberoamericanos para la Educación, la Ciencia y la Cultura (OEI).

PESSINI, Leocir; BARCHIFONTAINE, Chistian de Paul de. Problemas atuais de bioética. 8. ed. revista e ampliada - São Paulo: Centro Universitário São Camilo: Loyola, 2007. 584p.

POSTMAN, Neil. Tecnopólio: a rendição da Cultura à tecnologia. Tradução de Reinaldo Guarany. São Paulo: Nobel, 1994.

RODRIGUEZ, Carlos Arteaga. As inovações no ensino superior e a formação do médico professor. 2003. Dissertação (Mestrado em Educação) - Centro de Teologia e Ciências Humanas. Pontifícia Universidade Católica do Paraná, Curitiba 
SANVITO, Wilson L. A medicina tem cura? Uma abordagem crítica da medicina contemporânea. Editora Ateneu, 1994.

SCHNORR, Samuel Molina; RODRIGUES, Carla Gonçalves. Ciência, Tecnologia e Sociedade na contemporaneidade: implicações educacionais tramadas ao pósestruturalismo. R. Bras. de Ensino de C\&T vol 8, núm. 3, mai-ago.2015 ISSN 1982-873X

SGRECCIA, Elio. Manual de bioética: fundamentos e ética biomédica. São Paulo: Edições Loyola, 2002.

SILVEIRA, Rosemari Monteiro Castilho Foggiatto; BAZZO, Walter Antônio. Educação Tecnológica: Qual o seu papel? In: XXXV Congresso Brasileiro de Educação em Engenharia, 2007, Curitiba.

SORDI, Maria Regina Lemes de; BAGNATO, Maria Helena Salgado. Subsídios para a formação crítico-reflexiva na área da saúde: o desafio da virada do século. Rev. Latina-Am. Enferm. 1998; 6(2):83-8.

Recebido: 2016-04-07

Aprovado:.2017-05-16

DOI: $10.3895 /$ rbect.v10n2.3879

Como citar: ZIMMERMANN, M. H.; SILVEIRA, R. M. C. F. Enfoque CTS, o ensino médico e a ética de responsabilidade de Hans Jonas. Revista Brasileira de Ensino de Ciência e Tecnologia, v. 10, n. 2, 2017. Disponível em: <https://revistas.utfpr.edu.br/rbect/article/view/3879>. Acesso em: xxx.

Correspondência:

Direito autoral: Este artigo está licenciado sob os termos da Licença Creative Commons-Atribuição 4.0 Internacional. 